\title{
Critical Incident Management by Teleconference: Identifying Non-Technical Skills
}

\author{
Graham Coull, John Tripp, Michael Davies \\ Morgan Stanley \\ john.tripp@morganstanley.com
}

\author{
Rhona Flin \\ University of Aberdeen \\ r.flin@abdn.ac.uk
}

\begin{abstract}
Motivation - appears to have been very little research into the decision making, situation awareness and communication skills required to manage critical incidents which have to be resolved by teleconference. Research approach - task analysis methods including interviews with subject matter experts. Research limitations/ implications - this is a new project and only the background, rationale and first stage of development are presented. Originality/ Value - Non-technical skills framework for TCIM (Teleconference Critical Incident Management) provides a curriculum for training, the basis for an assessment and feedback tool and a method for incident analysis. Take away message - non-technical frameworks of cognitive and social skills can be adapted for teleconference decision making.
\end{abstract}

\section{INTRODUCTION}

Global commercial organisations, such as banks, rely on large scale, interlinked IT systems to support their financial and infrastructure management operations. These are typically built on geographically dispersed hardware platforms running shared, often-interdependent software systems, operated by technical support staff and engineers. When any kind of critical system disruption occurs requiring an immediate response that cannot be resolved through standard operational procedures, specialist teams of experts are rapidly configured to engage in a problem solving task to provide a response to the situation. These experts are not co-located, so they are required to communicate by a teleconference facility, as well as some computer-supported networks. Depending on the complexity and scale of the problem, there could be as many as 50 individuals on a teleconference (the call), phoning in from different teams and locations, possibly in different time zones across the globe. The person leading the call has to enable this very large group of specialists (interacting only by telephone) to engage in effective situation assessment, problem solving and decision making, often for complex technical problems and under considerable time pressure.

As in many other technical professions, the training of these IT specialists is predominantly of a technical nature but an examination of their CIM task requirements revealed that these systems experts also require cognitive and social (nontechnical) skills to work effectively on the critical incident call. While there have been a number of investigations into the skills required for critical incident management (Flin, 1996), there has been little research into the non-technical skills required for this type of critical incident.

\section{METHODS}

The methods used to develop the prototype skill set were based on the task analysis techniques used in previous studies to develop taxonomies of cognitive and social skills for safety-critical occupations such as airline pilots, surgeons and anaesthetists (see Flin et al, 2008). Semi-structured interviews were conducted with several subject matter experts in an international banking company who had experience of leading critical incident management teleconferences to identify task requirements and a basic list of skills. Four critical incident interviews (Crandall et al, 2006) were carried out by an industrial psychologist with senior managers who had experience of CIM calls. These were recorded and then analysed to identify effective and ineffective behaviours for effective incident resolution. Documentary analysis was also conducted using existing competence frameworks to extract a list of non-technical skills. 


\section{FINDINGS}

Based on these sources of cognitive and social skills, a panel of systems experts and an industrial psychologist developed a preliminary non-technical skills framework which has four main categories of skills, each of which is subdivided into three elements. Each element has examples of good and poor behaviours.

\begin{tabular}{|l|l|}
\hline CATEGORIES & Example ELEMENT and definition \\
\hline Situation Awareness & $\begin{array}{l}\text { Gathering information - from the application and } \\
\text { infrastructure environment and people }\end{array}$ \\
\hline Decision Making & $\begin{array}{l}\text { Considering options - generating alternative } \\
\text { possibilities or courses of action. Assessing hazards } \\
\text { and weighing up threats and benefits of potential } \\
\text { actions }\end{array}$ \\
\hline Leadership & $\begin{array}{l}\text { Establishing a shared understanding - ensuring } \\
\text { that the team has necessary information to carry out } \\
\text { the resolution, understand it and that an acceptable } \\
\text { shared' big picture' of the case is held by team } \\
\text { members }\end{array}$ \\
\hline $\begin{array}{l}\text { Coping with pressure - retaining a calm } \\
\text { demeanour when under pressure and demonstrating } \\
\text { to the team that the situation is under control. } \\
\text { Adopting a suitably forceful manner, if appropriate, } \\
\text { without undermining the role of other team } \\
\text { members. }\end{array}$
\end{tabular}

The Teleconference CIM skills framework is now being used as the basis of a two day training course which is similar to the Crew Resource Management courses used in aviation (see Flin et al 2008). It is also being adapted as an individual and team debriefing tool for critical incidents that are managed by teleconference and the resulting data will be used for further refinement of the taxonomy.

\section{CONCLUSIONS}

For large IT teams who communicate via teleconferencing to make critical decisions to resolve systems problems, a key set of cognitive and social skills are required for effective task performance. These can be identified using task analysis methods and the resulting skills frameworks can then be used to enhance training and assessment of decision making performance in live or simulated conditions.

\section{ACKNOWLEDGEMENTS}

We would like to thank those managers and systems experts who took part in interviews for this study.

\section{REFERENCES}

Crandall, B, Klein, G., \& Hofmann, R. (2006) Working Minds. Cambridge: MIT Press.

Flin, R. (1996) Sitting in the Hot Seat. Leaders and Teams for Critical Incident Management. Chichester: Wiley.

Flin, R., O’Connor, P. \& Crichton, M. (2008) Safety at the Sharp End: A Guide to Non-Technical Skills. Aldershot: Ashgate. 